\title{
Caracteres morfológicos de soja e braquiária consorciadas sob subdoses de fluazifop-p-butil
}

\author{
Morphologic characters of soybean and Brachiaria intercropped under \\ reduced rates of fluazifop-p-butyl
}

\author{
Andréia Cristina Silva ${ }^{1}$ Lino Roberto Ferreira ${ }^{2}$ Antônio Alberto da Silva ${ }^{2}$ \\ Alessandra Ferreira Belo ${ }^{3}$ Carlos Sigueyuki Sediyama ${ }^{4}$
}

\section{RESUMO}

\begin{abstract}
A degradação das pastagens é um dos maiores problemas da pecuária, afetando diretamente a sustentabilidade do setor. Como alternativas de recuperação, tem sido proposta a utilização de culturas anuais em consórcio com forrageiras. No entanto, para a viabilização do consórcio, é necessário o manejo adequado da forrageira minimizando a competição com a cultura. Objetivou-se, neste trabalho, avaliar os efeitos da aplicação do fluazifop-p-butil em caracteres morfológicos de Brachiaria brizantha e soja, cultivadas em consórcio. O experimento foi realizado em Coimbra-MG. Foram avaliadas seis doses de fluazifop-p-butil (0, 18, 36, 54, 72 e $\left.90 \mathrm{~g} \mathrm{ha}^{-1}\right)$ aplicadas em duas épocas (21 e 28 dias após a emergência da soja-DAE) e 2 testemunhas (soja e braquiária em monocultivo e capinadas). Não foi verificada interação entre doses e épocas de aplicação. Todavia, as doses 0,18 e $36 \mathrm{~g} \mathrm{ha}^{-1}$, influenciaram negativamente $o$ índice de área foliar (IAF), a biomassa seca das folhas, da haste + pecíolos e das vagens das plantas de soja. O IAF, a biomassa seca das folhas (BSF), o número, o comprimento e a biomassa seca dos colmos (BSC) da B. brizantha, foram afetados pelas doses e épocas de aplicação. A aplicação aos 28 DAE foi mais prejudicial à $\boldsymbol{B}$. brizantha do que quando realizada aos 21 DAE. Na avaliação efetuada aos 53 DAE, para as variáveis $B S F$, $B S C$ e IAF, as doses 0,18 e $36 \mathrm{~g} \mathrm{ha}{ }^{-1}$, aplicadas aos 21 DAE, e as

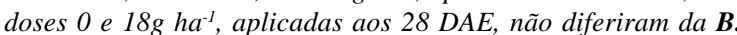
brizantha em monocultivo. Aos 78 DAE, somente a dose 0 não diferiu da B. brizantha em monocultivo nas duas épocas de aplicação. Ao utilizar $36 \mathrm{~g} \mathrm{ha}^{-1}$ de fluazifop-p-butil, houve o favorecimento da B. brizantha em relação à soja. Por outro lado, a dose de $54 \mathrm{~g} \mathrm{ha}^{-1}$ de fluazifop-p-butil privilegiou a soja em detrimento da B. brizantha. Nas condições em que foi conduzido o ensaio a faixa ideal do herbicida, visando o consórcio, foi de $40 \mathrm{~g} \mathrm{ha} \mathrm{I}^{-1}$ de fluazifop-p-butil.
\end{abstract} Palavras-chave: Glycine max, Brachiaria, herbicida, consórcio,
manejo.

\begin{abstract}
Pasture degradation is one of the most important problems, affecting directly the sustainability of animal production. As one of the alternatives for the recovery of the degraded pasture, the use of annual crops intercropped with forages has been proposed. However, for the viabilization of the intercropping it is necessary the adequate management of the forage to reduce the competition with the crop, searching both development. The objective of this work was to evaluate the effects of fluazifop-p-butyl on the morphology of Brachiaria brizantha and soybean grown intercropped. The experiment was conducted at Coimbra-MG to evaluate six doses of fluazifop-p-butil $(0,18$, 36, 54, 72 and $90 \mathrm{~g} \mathrm{ha}^{-1}$ ) applied at two times ( 21 and 28 days after soybean emergence - DAE). Additionally, two control treatments were included: soybean and B. brizantha in monocrop kept free of weeds. The time of application did not affect the efficacy of herbicide doses. The treatment without herbicide or at lower doses, affected negatively the leaf area index (LAI), leaves biomass, stem + petioles biomass and pods biomass of the soybean plants. The LAI, leaves biomass (LB), stems number, stem length and stems biomass $(S B)$ of the $B$. brizantha, were affected by the doses and time of application. The application at 28 DAE caused more injury to the $\boldsymbol{B}$. brizantha than at 21 DAE. It was verified that at $53 \mathrm{DAE}$ the doses 0,18 and $36 \mathrm{~g} \mathrm{ha}^{-1}$, applied at $21 \mathrm{DAE}$, and the doses 0 and $18 \mathrm{~g} \mathrm{ha}^{-1}$, applied at $28 \mathrm{DAE}$ were similar to that of control (B. brizantha monocrop) for SB, LB and LAI. The dose of $36 \mathrm{~g} \mathrm{ha}^{-1}$ of fluazifop-p-butil benefited the B. brizantha compared to soybean. For the other hand the dose of $54 \mathrm{~g} \mathrm{ha}^{-1}$ of fluazifop-p-butil benefited the soybean compared to B. brizantha. For the conditions of this experiment, the ideal dose of fluazifop-
\end{abstract}

${ }^{1}$ Engenheiro Agrônomo, Mestre em Produção Vegetal, Doutorando em Fitotecnia, Universidade Federal de Viçosa (UFV), 36571-000 Viçosa-MG. E-mail: andreia@vicosa.ufv.br. Autor para correspondência.

${ }^{2}$ Engenheiro Agrônomo, Doutor, Professor Adjunto do Departamento de Fitotecnia, UFV.

${ }^{3}$ Engenheiro Agrônomo, Mestrando do Departamento de Fitotecnia, UFV.

${ }^{4}$ Engenheiro Agrônomo, PhD, Professor Titular do Departamento de Fitotecnia, UFV. 
p-butil for the intercropping establishment was $40 \mathrm{~g} \mathrm{ha}^{-1}$ of fluazifop-p-butil.

Key words: Glycine max, Brachiaria, herbicide, intercropping, management.

\section{INTRODUÇÃO}

A degradação das pastagens é um dos maiores problemas da pecuária no Brasil. Estima-se que $80 \%$ dos 60 milhões de hectares de pastagens cultivadas no Brasil Central, que respondem por $55 \%$ da produção nacional de carne, apresentam-se degradados ou em processo de degradação, o que afeta a sustentabilidade da pecuária (MACEDO et al., 2000).

Uma das alternativas propostas para a recuperação de pastagens degradadas, é a utilização de culturas anuais em cultivos seqüenciais ou simultâneos como sistemas de produção. A produção de grãos das culturas, o aproveitamento da adubação residual e o preparo de solo mais elaborado contribuem para a diminuição dos custos e maior eficiência de recuperação das pastagens degradadas (KICHEL et al., 2000; MACEDO et al., 2000; PORTES et al., 2000; OLIVEIRA et al., 2001). O sucesso dessa tecnologia está também associada à quebra do ciclo de pragas e doenças, melhoria das propriedades físicas do solo, maior eficiência no uso de máquinas, diversificação do sistema produtivo e aumento da produtividade do agronegócio, tornandoo sustentável em termos econômicos e agroecológicos (KICHEL et al., 2000).

A interação de leguminosas e gramíneas é aconselhável não somente para o consumo dos animais em pastejo mas também como forma de adicionar nitrogênio ao solo (ZIMMER \& EUCLIDES FILHO, 1997) uma vez que as gramíneas tropicais adicionam continuamente ao solo materiais com alta razão $\mathrm{C} / \mathrm{N}$, conduzindo à imobilização do nitrogênio e à construção de matéria orgânica recalcitrante (ROBERTSON et al., 1997).

O sistema de consórcio entre culturas é usado em muitas partes do mundo e, em geral, tem se mostrado mais produtivo que o monocultivo. Entretanto, combinações de certas culturas resultam em aumento da competição entre as culturas por água, luz e nutrientes, conduzindo à redução da produtividade, tornando algumas culturas inapropriadas para o consórcio (FUKAI \& TRENBATH, 1993).

Dessa forma, para a viabilização do consórcio entre a cultura da soja e a B. brizantha, é necessário o manejo adequado da forrageira minimizando a competição com a cultura, permitindo boa produtividade da soja e de biomassa da B. brizantha.

O objetivo deste trabalho foi avaliar os efeitos de doses do graminicida fluazifop-p-butil sobre caracteres morfológicos de B. brizantha e soja cultivadas em consórcio.

\section{MATERIAL E MÉTODOS}

O experimento foi realizado no ano agrícola 2002/2003, na Estação Experimental de Coimbra-MG, em solo classificado como Argissolo VermelhoAmarelo Câmbico distrófico, fase terraço, cujas principais características físicas e químicas são: $\mathrm{pH}$ em água de 4,9; 3,11dag $\mathrm{kg}^{-1}$ de matéria orgânica; V de $34 \%$; teores de $\mathrm{P}, \mathrm{K}, \mathrm{Zn}, \mathrm{Fe}, \mathrm{Mn}, \mathrm{Cu}, \mathrm{B}$ de 14,8 ; 80,$0 ; 2,2 ; 33,2 ; 27,6 ; 1,2$ e $0,37 \mathrm{mg} \mathrm{dm}^{-3}$ e de $\mathrm{Ca}, \mathrm{Mg}$, $\mathrm{H}+\mathrm{Al}$ de 1,4; 0,6 e 4,29 de cmolc $\mathrm{dm}^{-3}$, respectivamente.

O experimento foi implantado em sistema de plantio direto, após a dessecação química da cobertura vegetal composta por plantas daninhas (Artemisia verlotorum, Brachiaria plantaginea, Cynodon dactylon, Cyperus esculentus, Commelina benghalensis, Andropogon bicornis, Paspalum conjugatum, Melinis minutiflora, Sorghum arundinaceum, Bidens pilosa e Raphanus raphanistrum).

A semeadura da soja (cultivar UFV-16) e da $\boldsymbol{B}$. brizantha (cultivar MG-5) foram realizadas simultaneamente em 25/11/02. O espaçamento utilizado foi de $0,55 \mathrm{~m}$ entre as linhas de soja, obtendose estande de 250.000 plantas ha $^{-1}$, sendo a braquiária semeada entre as linhas da soja ( $6 \mathrm{~kg} \mathrm{ha}^{-1}$ de sementes). A unidade experimental foi composta por uma área de $26,4 \mathrm{~m}^{-2}$. Para o semeio, utilizou-se a semeadora Semeato previamente ajustada.

As sementes de soja foram inoculadas com as estirpes SEMIA 587 e SEMIA 5019 de Bradyrhizobium japonicum. A adubação foi feita na semeadura, aplicando-se $250 \mathrm{~kg} \mathrm{ha}^{-1}$ da formulação 828-16. Durante o desenvolvimento do ensaio, com exceção do controle de plantas daninhas, foram efetuados todos os tratos culturais e fitossanitários necessários.

Para o controle de plantas daninhas dicotiledôneas, utilizou-se o herbicida fomesafen $\left(0,2 \mathrm{~kg} \mathrm{ha}^{-1}\right)$ em área total, aplicado aos 19 dias após a emergência da soja, ou seja, dois dias antes da aplicação do graminicida.

O delineamento experimental adotado foi o de blocos casualizados, com 14 tratamentos e

Ciência Rural, v.35, n.2, mar-abr, 2005. 
quatro repetições, seguindo o arranjo fatorial $6 \times 2+2$, seis doses de fluazifop-p-butil $(0,18,36,54,72$ e $90 \mathrm{~g} \mathrm{ha}^{-1}$ ) aplicadas aos 21 e 28 dias após a emergência da cultura da soja (DAE), e as testemunhas (B. brizantha e soja em monocultivo e capinadas). O fluazifop-p-butil foi aplicado com pulverizador costal pressurizado com $\mathrm{CO}_{2}$, equipado com barra de quatro bicos TT 110.02, espaçados em $0,5 \mathrm{~m}$, mantendo pressão constante de $2 \mathrm{KPa}$, aplicando-se o equivalente a $160 \mathrm{~L} \mathrm{ha}^{-1}$ de calda.

No estádio R5 da cultura da soja, segundo escala de FEHR et al. (1971), foram coletadas cinco plantas de soja em cada unidade experimental. As plantas foram desmembradas em haste + pecíolos, folhas e vagens. A área foliar das plantas amostradas foi determinada utilizando o medidor eletrônico de área foliar modelo LI 3100 da LI-COR, calculandose o índice de área foliar. A biomassa seca das partes amostradas foi obtida utilizando-se estufa de circulação forçada de ar a $70^{\circ} \mathrm{C} \pm 2{ }^{\circ} \mathrm{C}$, onde o material permaneceu até atingir peso de biomassa constante.

Para avaliação da $\boldsymbol{B}$. brizantha, foram realizadas amostragens aos 53 e 78 DAE. Foram coletadas as plantas contidas em $0,5 \mathrm{~m}$ de linha de plantio de todas as unidades experimentais. As plantas foram desmembradas em folhas e colmos. Foi determinada a área foliar, sendo os colmos medidos e contados, determinando-se a biomassa seca.

Os dados obtidos foram submetidos à análise de variância, sendo os dados referentes à $\boldsymbol{B}$. brizantha transformados para $\sqrt{\mathbf{x + 0 , 5}}$ antes da análise, à exceção da variável comprimento dos colmos. Para as estimativas dos parâmetros da regressão do modelo, utilizou-se o programa SIGMAPLOT. Foram adotados os modelos loglogístico e logístico. O modelo log-logístico equação 1 (SEEFELDT et al., 1995), apresenta quatro parâmetros, sendo $\mathrm{Y}_{0} \mathrm{o}$ limite inferior; a é a diferença entre o limite superior e o inferior; $b$ descreve o declive da curva em torno da concentração do produto que inibe $50 \%$ do crescimento do bioindicador $\left(\mathrm{I}_{50}\right)$ e $\mathbf{x}_{0}$ representa o $\mathrm{I}_{50}$. O modelo logístico - equação 2 (FINNEY, 1979) possui três parâmetros: a é denominado "nível de saturação"; $\mathrm{x}_{0}$ corresponde ao valor de $\mathrm{I}_{50}$; e b descreve o declive da curva em torno de $\mathrm{I}_{50}$.

$$
\mathbf{Y}=\mathbf{Y}_{\mathbf{0}}+\frac{\mathbf{a}}{\mathbf{1}+\left(\frac{\mathbf{X}}{\mathbf{x}_{\mathbf{0}}}\right)^{\mathbf{b}}} \text { (Eq. 1) } \mathbf{Y}=\frac{\mathbf{a}}{\mathbf{1}+\left(\frac{\mathbf{X}}{\mathbf{x}_{\mathbf{0}}}\right)^{\mathbf{b}}} \text { (Eq. 2) }
$$

Para comparar os tratamentos com as testemunhas, foi utilizado o teste de Dunnett a 5\% de probabilidade de erro.

\section{RESULTADOS E DISCUSSÃO}

Não houve interação entre doses e épocas de aplicação para nenhuma das variáveis avaliadas, indicando que a época de aplicação não interferiu na eficácia das doses.

Para as avaliações realizadas no estádio R5 da cultura (início de enchimento de grãos), correspondentes à partição de assimilados das plantas de soja, ou seja, biomassa seca das folhas (BSF), da haste + pecíolos (BSHP) e das vagens (BSV) (Figura 1-A), foi verificado somente efeito de doses.

O acúmulo de biomassa nos diferentes órgãos das plantas de soja foi influenciado pelas doses do fluazifop-p-butil, evidenciando o poder de competição da $\boldsymbol{B}$. brizantha com a soja. Em todos os tratamentos, no estádio R5, verificou-se maior alocação de biomassa para haste + pecíolos, seguido pelas folhas e posteriormente pelas vagens. Na dose 0 de fluazifopp-butil, ou seja, onde houve maior competição com a forrageira, observa-se pelo parâmetro $\mathrm{Y}_{0}$, valores de 7,122; 4,3246 e 2,2901g planta ${ }^{-1}$ para BSHP, BSF e $\mathrm{BSV}$, respectivamente, havendo maior queda de biomassa para a haste, como pode ser observado pelo parâmetro "a" da equação. MELGES et al. (1989) demonstraram que o acúmulo de biomassa seca nos diferentes órgãos da soja é seqüencial. Inicialmente, as raízes e folhas são os drenos metabólicos preferenciais, ocorrendo posteriormente mudança do dreno para a haste, seguido pelas vagens. Verificaram ainda que diferentes níveis de sombreamento alteraram a partição de assimilados entre os órgãos, porém, manteve-se a ordem dos drenos preferenciais, como constatado neste trabalho. A redução da biomassa nos diferentes órgãos da soja apresentou a mesma tendência, mostrando que a competição com a forrageira afetou de forma semelhante os diferentes órgãos da soja. DUARTE et al. (1995), estudando o consórcio das cultivares de soja IAC-8 e Júpiter com B. brizantha, verificaram redução de biomassa e do IAF da cultura no estádio R5, não verificando diferenças de crescimento durante os primeiros 75 dias de desenvolvimento. Todavia, a partir de 75 dias, a B. brizantha cv. Marandú, de crescimento semi ereto tendeu a superar a soja em altura. Segundo os autores, as relações de competição entre cultivos anuais e pastagens estabelecidos de forma simultânea, variam com a morfologia e velocidade de crescimento inicial das espécies utilizadas.

Também não houve efeito de época de aplicação do fluazifop-p-butil para o IAF (Figura 1B), porém houve efeito de doses. Nas doses 0 , e $18 \mathrm{~g}$ ha $^{-1}$ de fluazifop-p-butil, o IAF permaneceu em torno de 3, estabilizando-se por volta de 5 a partir da dose 


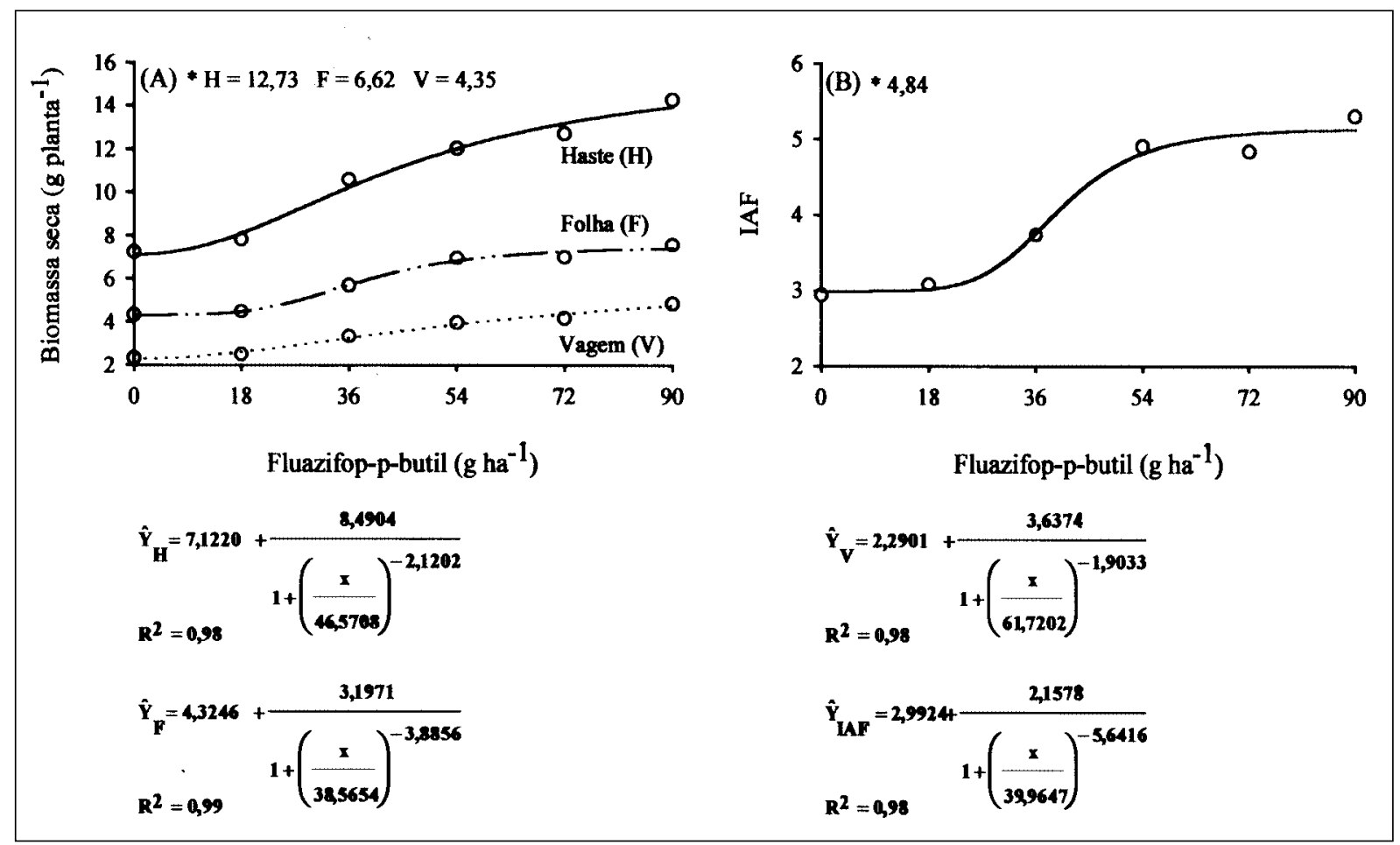

Figura 1 - Biomassa seca das folhas, haste + pecíolos e vagens (A) e o IAF (B) da soja consorciada com B. brizantha, no estádio R5 da soja, em função de doses do fluazifop-p-butil e, respectivas testemunhas em monocultivo (*). Coimbra-MG, 2003.

de 54g ha-1. SERT (1992) observou redução da área foliar de três cultivares de soja quando submetidas a sombreamento, justificando a redução pelo menor número de folhas, devido à abscisão destas. MELGES et al. (1989) também atribuíram a redução do IAF em plantas sombreadas à redução do número de folhas.

Quanto ao desenvolvimento da $\boldsymbol{B}$. brizantha, verificaram-se efeitos de doses e épocas de aplicação do fluazifop-p-butil para a BSF e biomassa seca dos colmos (BSC). A mesma tendência foi constatada para BSF (Figura 2-A e B) e BSC (Figura 2-C e D), observando-se decréscimo de biomassa com o incremento das doses, sendo que no intervalo entre as duas amostragens, ocorreu aumento de biomassa para todos os tratamentos, até mesmo nas doses mais altas, o que foi atribuído às plantas emergidas posteriormente à aplicação. Convém salientar que a recomendação do fluazifop-p-butil é de 90 a $250 \mathrm{~g} \mathrm{ha}^{-1}$ segundo RODRIGUES \& ALMEIDA (1998), portanto a maior dose utilizada neste experimento correspondeu ao limite mínimo recomendado para a cultura $\left(90 \mathrm{~g} \mathrm{ha}^{-1}\right)$.

Aos 53 DAE, as doses 0,18 e $36 \mathrm{~g} \mathrm{ha}^{-1}$ aplicadas aos 21 DAE da cultura, e as doses 0 e $18 \mathrm{~g}$ ha $^{-1}$ aplicadas aos 28 DAE, não diferiram da $\boldsymbol{B}$. brizantha em monocultivo, evidenciando o melhor controle da forrageira na aplicação aos 28 DAE. Todavia, aos 78 DAE somente a dose 0 não diferiu da B. brizantha em monocultivo. Este resultado foi atribuído à paralisação do crescimento da $\boldsymbol{B}$. brizantha promovido pelo fluazifop-p-butil, associado ao efeito de sombreamento da cultura, afetando de forma semelhante os colmos e as folhas.

A BSF (Figura 2-A) da B. brizantha foi superior à BSC (Figura 2-C) na avaliação efetuada aos 53 DAE, sendo que aos 78 DAE (Figuras 2-B e D) observa-se o inverso, ou seja maior alocação para o colmo. PORTES et al. (2000) verificaram tanto para braquiária em monocultivo como consorciada com cereais, gradual redução da relação folha e colmo com maior partição para as folhas inicialmente, observando-se queda acentuada, com partição em benefício dos colmos, como constatado nesse trabalho.

Os gráficos referentes ao acúmulo de biomassa seca da B. brizantha e da soja evidenciam que a dose apropriada para permitir o acúmulo de biomassa de ambas as espécies permaneceu entre 36 e $54 \mathrm{~g} \mathrm{ha}^{-1}$ de fluazifop-p-butil. Ao utilizar $36 \mathrm{~g} \mathrm{ha}^{-1} \mathrm{de}$ fluazifop-p-butil, houve o favorecimento da $\boldsymbol{B}$. brizantha em relação à soja. Por outro lado, a dose de

Ciência Rural, v.35, n.2, mar-abr, 2005. 


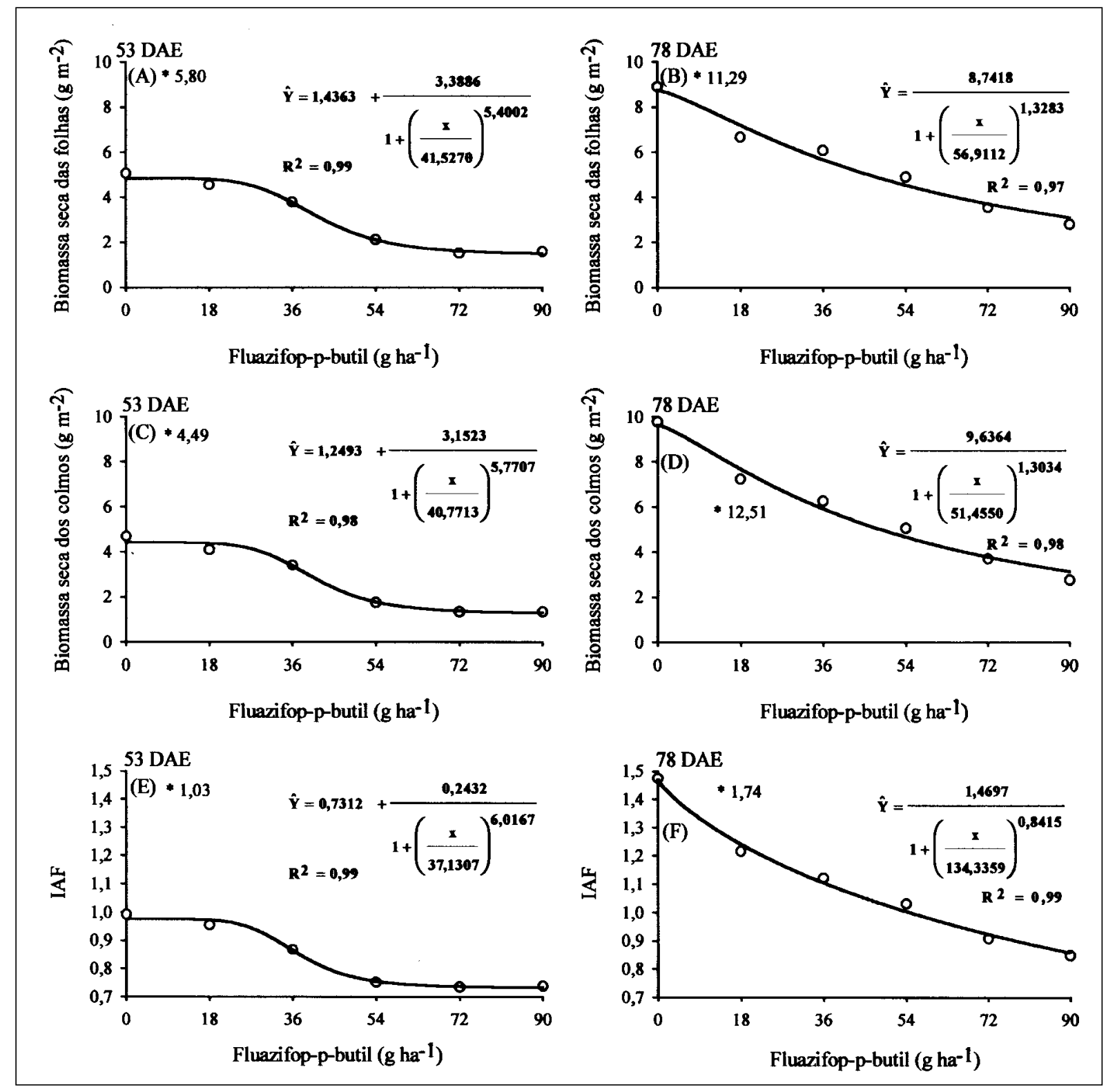

Figura 2 - Biomassa seca das folhas (A e B) e colmos (C e D) e o IAF (E e F) da B. brizantha consorciada com a cultura da soja, em função de doses do fluazifop-p-butil, em duas épocas de avaliação (53 e 78 DAE) e, respectivas testemunhas em monocultivo (*). CoimbraMG, 2003.

$54 \mathrm{~g} \mathrm{ha}^{-1}$ de fluazifop-p-butil privilegiou a soja em detrimento da B. brizantha.

O índice de área foliar da B. brizantha (Figura 2-E e F) apresentou a mesma tendência das folhas e colmos, diferindo nos mesmos tratamentos em relação à B. brizantha em monocultivo, nas duas avaliações, evidenciando a redução da área do solo coberta pela forrageira e conseqüente diminuição da competição por luz com a cultura.

Aos 53 DAE (Figura 3-A), constatou-se queda acentuada do número de colmos a partir da dose de $54 \mathrm{~g} \mathrm{ha}^{-1}$ do fluazifop-p-butil. Nas doses $0,18 \mathrm{e}$ $36 \mathrm{~g} \mathrm{ha}^{-1}$, não houve diferença em relação à $\boldsymbol{B}$. brizantha em monocultivo nas duas épocas de aplicação. No entanto, aos 78 DAE (Figura 3-B) somente o tratamento na dose 0 do fluazifop-p-butil não diferiu da B. brizantha em monocultivo, evidenciando o efeito do herbicida no perfilhamento da forrageira, associado ao sombreamento da soja. DIAS FILHO (2000) verificou maior perfilhamento da $\boldsymbol{B}$. brizantha a pleno sol em relação às plantas submetidas a $30 \%$ de sombreamento.

Ciência Rural, v.35, n.2, mar-abr, 2005. 

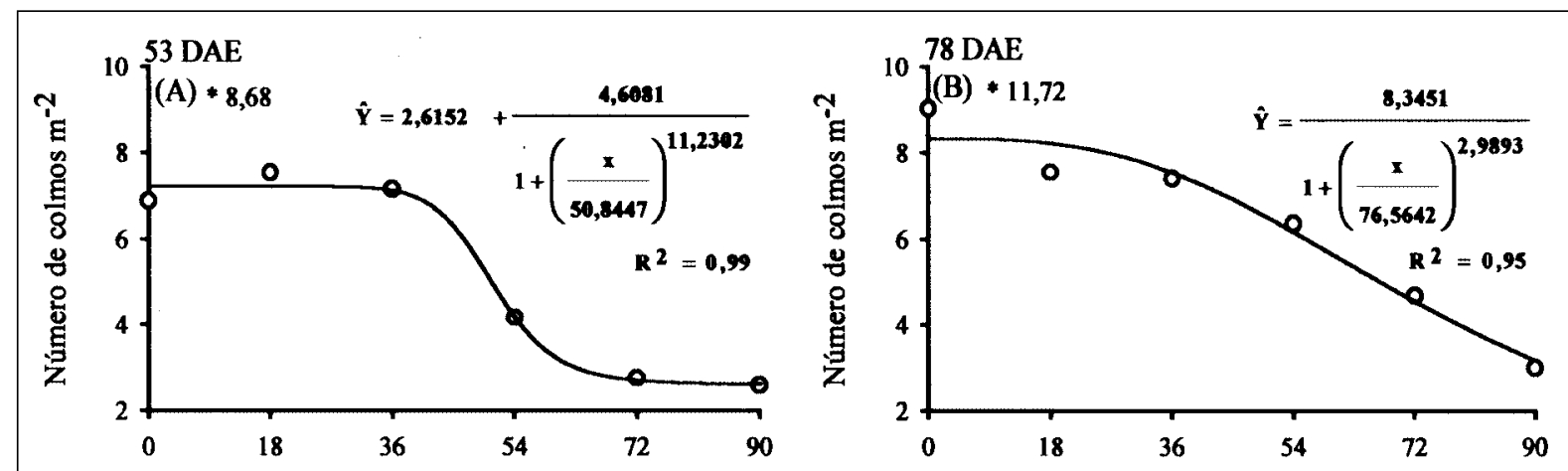

Fluazifop-p-butil $\left(\mathrm{g} \mathrm{ha}^{-1}\right)$
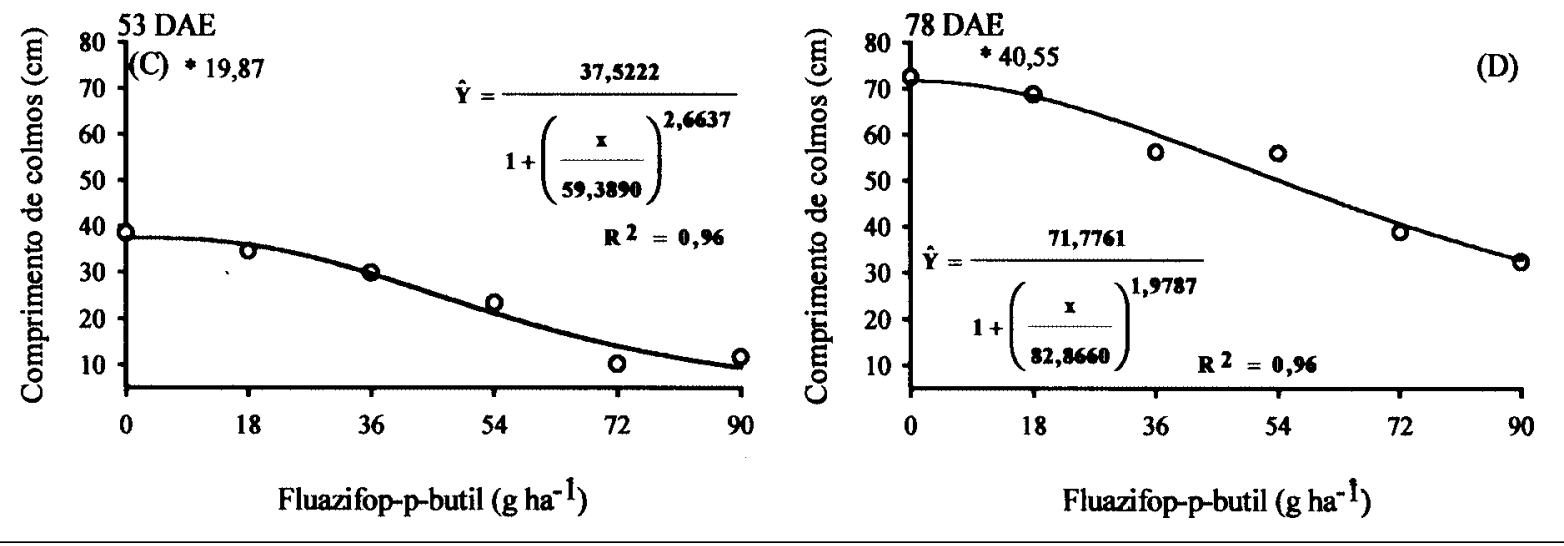

Figura 3 - Número (A e B) e comprimento (C e D) de colmos da B. brizantha consorciada com a cultura da soja, em função de doses de fluazifop-p-butil, em duas épocas de avaliação (53 e 78 DAE) e, respectivas testemunhas em monocultivo (*). Coimbra-MG, 2003.

Quanto ao efeito dos tratamentos no comprimento do colmo, verificou-se redução deste com o aumento das doses (Figura 3-C e D). O parâmetro "a" da equação evidencia altura de 37,5222 e $71,7761 \mathrm{~cm}$ nas avaliações efetuadas aos 53 e 78 DAE respectivamente, para a $\boldsymbol{B}$. brizantha submetida à dose 0 do fluazifop-pbutil. A altura da B. brizantha praticamente dobrou entre as duas avaliações, refletindo o efeito do estiolamento provocado pelo sombreamento da soja. Não houve diferença em relação à B. brizantha em monocultivo, o que é explicado pois esta apresentou altura intermediária, uma vez que não sofreu efeito do sombreamento da cultura.

Os resultados deste trabalho estão de acordo com os de PORTES et al. (2000) os quais verificaram que a B. brizantha $\mathrm{cv}$. Marandu em consórcio com cereais sofreu efeito da competição, resultando em redução no número de perfilhos, do IAF assim como da biomassa seca das folhas e colmos em relação à testemunha em monocultivo.
A alta sensibilidade da $\boldsymbol{B}$. brizantha ao sombreamento, em parte, pode ser atribuída ao mecanismo de fixação do $\mathrm{CO}_{2}$ atmosférico (metabolismo $\mathrm{C}_{4}$ ), o que torna essa espécie altamente exigente em luz. $\mathrm{O}$ atraso no crescimento promovido pelo fluazifop-p-butil impediu a forrageira de superar a cultura em altura, tendo seu desenvolvimento reduzido pelo sombreamento.

\section{CONCLUSÕES}

Os resultados obtidos permitem concluir que o acúmulo de biomassa nos diferentes órgãos das espécies consorciadas foi influenciado pelo manejo da B. brizantha e da soja. Ao utilizar $36 \mathrm{~g} \mathrm{ha}^{-1}$ de fluazifop-p-butil, houve o favorecimento da $\boldsymbol{B}$. brizantha em relação à soja. Por outro lado, a dose de $54 \mathrm{~g} \mathrm{ha}^{-1}$ de fluazifop-p-butil privilegiou a soja em detrimento da B. brizantha. Nas condições em que foi conduzido o ensaio, a faixa ideal do herbicida, visando o consórcio, foi de $40 \mathrm{~g} \mathrm{ha}^{-1}$ de fluazifop-pbutil.

Ciência Rural, v.35, n.2, mar-abr, 2005. 


\section{REFERÊNCIAS BIBLIOGRÁFICAS}

DIAS FILHO, M.B. Growth and biomass allocation of the 44 grasses Brachiaria brizantha and B. humidicola under shade. Pesq Agropec Bras, v.35, n.12, p.2335$2341,2000$.

DUARTE, J.M. et al. Producción de maíz (Zea mays L.), soya (Glycine max L.) y caupi (Vigna unguiculata (L.) Walp) sembrados en asociación con gramíneas en el trópico húmedo. Pasturas Tropicales, v.17, n.2, p.12-19, 1995.

FEHR, W.R. et al. Stage of development descriptions for soybeans, Glycine $\max ($ L.) Merrill. Crop Sci, v.11, p.929-931, 1971.

FINNEY, D.J. Bioassay and the practice of statistical inference. Int Stat Rev, v.47, n.1, p.1-12, 1979.

FUKAI, S.; TRENBATH, B.R. Process determining intercrop productivity and yields of component crops. Field Crops Res, v.34, p.247-271, 1993.

KICHEL, A.N. et al. Produção de bovinos de corte com a integração agricultura x pecuária. In: SIMPÓSIO DE FORRAGICULTURA E PASTAGENS: TEMAS EM EVIDÊNCIAS, 1., 2000, Lavras. Anais... Lavras : UFLA, 2000. 369p. p.51-68.

MACEDO, M.C.M. et al. Degradação e alternativas de recuperação e renovação de pastagens. Dourados : EmbrapaCPAO, 2000. 4p. (Embrapa-CPAO. Comunicado Técnico, 62).
MELGES, E. et al. Desenvolvimento e partição de assimilados em Glycine max crescida sob quatro densidades de fluxo radiante. Pesq Agrop Bras, v.24, n.9, p.1081-1087, 1989.

OLIVEIRA, I.P. et al. Palhada no sistema Santa Fé. Goiânia : Embrapa-CNPAF, 2001. 4p. (Embrapa-CNPAF. Informações Agronômicas, 93).

PORTES, T.A. et al. Análise do crescimento de uma cultivar de braquiária em cultivo solteiro e consorciado com cereais. Pesq Agropec Bras, v.35, n.7, p.1349-1358, 2000.

ROBERTSON, F.A. et al. Nitrogen cycling in brigalow clay soils under pasture and cropping. Aust J Soil Res, v.35, p.1323-1339, 1997.

RODRIGUES, B.N.; ALMEIDA, F.S. Guia de herbicidas. 4.ed. Londrina : Edição dos autores, 1998. 648p.

SEEFELDT, S. et al. Log-logistic analysis of herbicide doseresponse relationships. Weed Technol, v.9, n.2, p.218-227, 1995.

SERT, M.A. Anatomia foliar e teores de clorofilas em três variedades de soja (Glycine max (L.) Merrill) em dois níveis de radiação solar. (Glycine max (L.) Merrill). 1992. 66f. Dissertação (Mestrado em Fisiologia Vegetal) - Universidade Federal de Viçosa.

ZIMMER, A.H.; EUCLIDES FILHO, K. As pastagens e a pecuária de corte brasileira. In: SIMPÓSIO INTERNACIONAL SOBRE PRODUÇÃO ANIMAL EM PASTEJO, 1997, Viçosa. Anais... Viçosa : José Alberto Gomide, 1997. 471p. p.349-379. 